\title{
Management of heart failure in family medicine
}

\section{Ksenija Tušek Bunc*}

Faculty of Medicine, University of Maribor, Maribor, Slovenia
RECEIVED:

July 28, 2015

ACCEPTED:

September 17, 2015

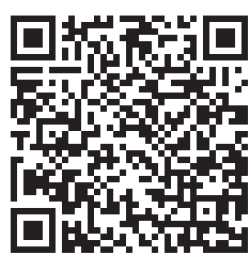

KEYWORDS: heart failure, management, family medicine.

CITATION: Cardiol Croat. 2015;10(9-10):203. | DOI: http://dx.doi.org/10.15836/ccar.2015.203

*ADDRESS FOR CORRESPONDENCE: Ksenija Tušek Bunc, Department of Family Medicine, Faculty of Medicine, University of Maribor, Taborska 8, 2000 Maribor, Slovenia. / E-mail: ksenija.tusek-bunc@guest.arnes.si / Phone: +386-41-699-690

ORCID: Ksenija Tušek Bunc, http://orcid.org/0000-0003-1474-9090

|||||||||||||||||||||||||||||||||||||||||||||||||||||||||||||||||||||||||||||||||||||||||||||||||||||||||||||||||||||||||||||||||||

Heart failure (HF) is associated with poor quality of life and prognosis. The most common causes of HF are coronary heart disease and arterial hypertension. European HF guidelines are based on the poor sensitivity and specificity of presenting signs and symptoms, and because better diagnostic procedures are now available to identify structural heart disease before it leads to clinical HF. ${ }^{1}$ Although the guidelines for diagnosing and treating of patients with HF have been known for years, their implementation is poor due to the lack of availability of certain investigations. In particular, echocardiography is the standard diagnostic tool used to diagnose HF, but its use by family practitioners is low due to lack of accessibility. Therefore, diagnosis of HF is often based on medical history and clinical examination. Unfortunately, the signs and symptoms of HF are relatively common and non specific, especially among the elderly. Their predictive value is low, requiring further diagnostic testing. This, and poor availability of echocardiography, means the diagnosis of HF is often arrived at a later stage of the disease. Family doctors could more quickly diagnose HF with use of brain natriuretic peptide (BNP) and NT-proBNP for screening, and with quick access to echocardiography. Management of HF consists first of nonpharmacological action (advice about healthy lifestyle), then reducing morbidity, improving survival and quality of life, reducing frequency of hospitalizations and, lastly, palliative care for advanced HF. Throughout this process, it is necessary to pay more attention to education, so these patients become equal partners in managing their disease. With appropriate diagnostic tests available, family practice doctors can competently and responsibly manage patients with HF.

1. McDonagh TA, Blue L, Clark AL, Dahlstrom U, Ekman I, Lainscak M, et al; European Society of Cardiology Heart Failure Association Committee on Patient Care. European Society of Cardiology Heart Failure Association Standards for delivering heart failure care. Eur J Heart Fail. 2011;13:235-41. DOI: http://dx.doi.org/10.1093/eurjhf/hfq221 